\title{
Comparative Effects of Curcumin and Tetrahydrocurcumin on Dextran Sulfate Sodium-induced Colitis and Inflammatory Signaling in Mice
}

ARTICLE

\author{
Joon-yeop Yang ${ }^{1}$, Xiancai Zhong ${ }^{1}$, Su-Jung Kim ${ }^{1}$, Do-Hee Kim ${ }^{1}$, Hyun Soo Kim ${ }^{1}$, Jeong-Sang Lee ${ }^{2}$, Hye-Won Yum ${ }^{1}$, \\ Jeewoo Lee ${ }^{1}$, Hye-Kyung $\mathrm{Na}^{3}$, Young-Joon Surh ${ }^{1}$
}

${ }^{1}$ Tumor Microenvironment Global Core Research Center, College of Pharmacy, Seoul National University, Seoul, ${ }^{2}$ Department of Functional Food and Biotechnology, College of Medical Science, Jeonju University, Jeonju, ${ }^{3}$ Department of Food Science and Biotechnology, College of Knowledge-based Services Engineering, Sungshin Women's University, Seoul, Korea

Background: Curcumin, a yellow ingredient of turmeric (Curcuma longa Linn, Zingiberaceae), has long been used in traditional folk medicine in the management of inflammatory disorders. Although curcumin has been reported to inhibit experimentally-induced colitis and carcinogenesis, the underlying molecular mechanisms remain largely unresolved.

Methods: Murine colitis was induced by dextran sulfate sodium (DSS) which mimics inflammatory bowel disease. Curcumin or tetrahydrocurcumin was given orally $(0.1$ or $0.25 \mathrm{mmol} / \mathrm{kg}$ body weight daily) for 7 days before and together with DSS administration (3\% in tap water). Collected colon tissue was used for histologic and biochemical analyses.

Results: Administration of curcumin significantly attenuated the severity of DSS-induced colitis and the activation of NF- $\mathrm{KB}$ and STAT3 as well as expression of COX-2 and inducible nitric oxide synthase. In contrast to curcumin, its non-electrophilic analogue, tetrahydrocurcumin has much weaker inhibitory effects.

Conclusions: Intragastric administration of curcumin inhibited the experimentally induced murine colitis, which was associated with inhibition of pro-inflammatory signaling mediated by NF-KB and STAT3.

(J Cancer Prev 2018;23:18-24)

Key Words: Curcumin, Dextran sulfate sodium-induced colitis, NF-אB, STAT3, Tetrahydrocurcumin

\section{INTRODUCTION}

Chronic inflammation has been implicated in pathogenesis of a variety of human malignancies. For instance, inflammatory bowel diseases (IBDs), such as ulcerative colitis and Crohn's disease, has been considered to contribute to human colorectal carcinogenesis (CRC). ${ }^{1}$ Dextran sulfate sodium (DSS)-induced mouse colitis mimics IBD, and has been widely used in evaluating the preventive and therapeutic potential of many anti-inflammatory agents. However, while DSS-induced colitis is necessary, it is not sufficient to induce CRC. Tanaka et al. ${ }^{2}$ developed a murine model of colitis-associated colon carcinogenesis, in which colonic tumors developed within 20 weeks by a single intraperitoneal injection of a genotoxic carcinogen azoxymethane, followed by $2.0 \%$ to $2.5 \%$ DSS in drinking water for seven consecutive days.

COX-2 has been known to play a pivotal role in pathogenesis of $\mathrm{CRC}^{3}$ Thus, the intake of the selective COX-2 inhibitor celecoxib resulted in the reduction of polyps in patients with familial adenomatous polyposis. ${ }^{4}$ Another enzyme involved in inflammation and oxidative stress is inducible nitric oxide synthase (iNOS). iNOS, which is overexpressed in colon cancer of humans and rodents, catalyzes the oxidative deamination of L-arginine to

Received February 19, 2018, Revised March 10, 2018, Accepted March 12, 2018

Correspondence to: Young-Joon Surh

Tumor Microenvironment Global Core Research Center, College of Pharmacy, Seoul National University, 1 Gwanak-ro, Gwanak-gu, Seoul 08826, Korea Tel: +82-2-880-7845, Fax: +82-2-883-2906, E-mail: surh@snu.ac.kr, ORCID: Young-Joon Surh, http://orcid.org/0000-0001-8310-1795

Copyright (c) 2018 Korean Society of Cancer Prevention

(c) This is an Open Access article distributed under the terms of the Creative Commons Attribution Non-Commercial License (http://creativecommons.org/licenses/by-nc/4.0) which permits unrestricted non-commercial use, distribution, and reproduction in any medium, provided the original work is properly cited. 
produce NO. ${ }^{5}$ Elevated levels of NO generated by iNOS induce inflammation, gene mutation, tissue damage, and malignant transformation. ${ }^{6}$ iNOS is likely to stimulate COX-2 activities, ${ }^{7}$ and hence affects colon carcinogenesis. ${ }^{6}$ Thus, COX-2 and iNOS are potential targets for the chemoprevention of colon cancer. ${ }^{5} \mathrm{NF}-\mathrm{KB}$ is a key transcription factor that mediates inflammatory gene expression, as well as immune responses. ${ }^{8}$ The $5^{\prime}$-promoter region of genes encoding COX-2 and iNOS contains putative $\mathrm{NF}-\mathrm{KB}$ binding sites. NF- $\mathrm{\kappa B}$ is mediated by several external stimuli that increase mitogen-activated protein kinase activity. ${ }^{9}$

Alleviating chronic inflammation represents an important component of current chemoprevention strategy. Though some non-steroidal anti-inflammatory drugs have protective effects against IBD, there has been an increased risk of heart attack or stroke observed in people intaking selective COX-2 inhibitors for 18 months or more. Thus, attention has been focused on the nutritional manipulation of colitis, and possibly inflammationassociated CRC. Numerous phytochemicals present in our diet have been shown to possess anti-inflammatory activities. ${ }^{10}$ One of the well-known dietary chemopreventive agents is curcumin, a yellow ingredient of the Indian spice turmeric (Curcuma longa Linn, Zingiberaceae). Curcumin has long been used in traditional folk medicine in the management of inflammatory disorders. ${ }^{11}$ It has been reported that curcumin is effective in ameliorating chronic gut inflammation in an animal model, and also in a randomized cross-over trial for the treatment of ulcerative colitis. ${ }^{12}$ Although there have been several reports demonstrating the inhibition of experimentally-induced colitis and carcinogenesis by curcumin, ${ }^{13-21}$ the underlying molecular mechanisms remain largely unresolved.

\section{MATERIALS AND METHODS}

\section{Materials}

Curcumin was supplied from LKT Laboratories (St. Paul, MN, USA). Tetrahydrocurcumin was prepared by conventional catalytic hydrogenation of curcumin in the presence of palladium on carbon. DSS (molecular weight, 36,000-50,000) was obtained from ICN Biochemicals, Inc. (Aurora, OH, USA) and MP Biomedical Inc. (Solon, OH, USA). Rabbit polyclonal COX-2 antibody was purchased from Cayman Chemical Co. (Ann Arbor, MI, USA), and iNOS antibody from BD Bioscience (Franklin Lakes, NJ, USA). Primary antibody for $\beta$-catenin was purchased from Santa Cruz Biotechnology (Santa Cruz, CA, USA). Anti-rabbit and anti-mouse horseradish peroxidase-conjugated secondary antibodies were products of Zymed Laboratories (San Francisco, CA, USA). An oligonucleotide probe containing the NF- $\mathrm{kB}$ sequence in the mouse COX-2 promoter region was obtained from Bionics (Seoul, Korea). An oligonucleotide probes harboring the STAT3 consensus sequence was obtained from Santa Cruz Biotechnology.

\section{Dextran sulfate sodium-induced colitis}

Male ICR mice ( 5 weeks of age) supplied by Central Lab. Animal Inc. (Seoul, Korea) were housed in climate-controlled quarters (24 $4^{\circ} \mathrm{C}$ at $50 \%$ humidity) with a 12 -h light/12-h dark cycle. Curcumin or tetrahydrocurcumin suspended in $0.05 \%$ carboxymethyl cellulose was given orally ( 0.1 or $0.25 \mathrm{mmol} / \mathrm{kg}$ body weight daily) for 7 days. Control animals were given vehicle in lieu of curcumin. After additional one week treatment, mice were given 3\% DSS in a tap water. Control mice were given a tap water. During the period of DSS treatment, all mice were subjected to following examinations on daily basis: weight measurement, fecal occult blood, and stool consistency. Mice were sacrificed by cervical dislocation. After measuring the length of the colorectal part, it was cut longitudinally and fixed with 10\% formalin before embedded in paraffin. Each section $(4 \mu \mathrm{m})$ was stained with H\&E.

\section{Western blot analysis}

Colon tissues were subjected to homogenization in ice-cold lysis buffer (150 mM NaCl, 0.5\% Triton-X 100, 50 mM, Tris-HCl [pH 7.4], $20 \mathrm{mM}$ ethylene glycol tetraacetic acid, $1 \mathrm{mM}$ dithiothreitol [DTT], $1 \mathrm{mM} \mathrm{Na}_{3} \mathrm{VO}_{4}$ and protease inhibitor cocktail tablet), and kysis for 30 minutes at $0^{\circ} \mathrm{C}$ followed by centrifugation at 14,000 rpm for 15 minutes. Supernatant was collected, and the total protein concentration was quantified by using the BCA protein assay kit (Pierce, Rockford, IL, USA). Cell lysates (30-50 $\mu \mathrm{g}$ protein) were boiled in SDS sample buffer for 5 minutes before electrophoresis on $8 \%$ to $12 \%$ SDS-polyacrylamide gel. Separated proteins were transferred to PVDF membrane, and the blots were blocked with 5\% fat-free dry milk PBS containing 0.1\% Tween-20 (PBST) or 1\% BSA in Tris-buffered saline containing 0.1\% Tween 20 (TBST) for 1 hour at room temperature. After washing with PBST or TBST buffer, the membranes were incubated for 2 hours at room temperature with $1: 4,000$ dilutions of primary antibody for actin, for 12 hours at $4^{\circ} \mathrm{C}$ with $1: 1,000$ dilutions of primary antibody for COX-2 or for 2 to 3 days at $4^{\circ} \mathrm{C}$ with $1: 700$ dilutions of primary antibody for iNOS. Blots were washed three times with PBST or TBST at 10 minutes intervals followed by incubation with $1: 5,000$ dilution of respective horseradish peroxidase conjugated secondary antibodies (rabbit, goat, or mouse) for 1 hour and again washed in PBST or TBST for three times. The corresponding proteins were visualized using an ECL detection kit 
obtained from Amersham Pharmacia Biotech (Buckinghamshire, $\mathrm{UK})$.

\section{Preparation of nuclear extracts}

The collected colon tissues of mice were homogenized in hypotonic buffer A (10 mM HEPES [pH 7.8], $10 \mathrm{mM} \mathrm{KCl,} 2 \mathrm{mM}$ $\mathrm{MgCl}_{2}, 1 \mathrm{mM}$ DTT, $0.1 \mathrm{mM}$ ethylenediaminetetraacetic acid [EDTA], and $0.1 \mathrm{mM}$ phenylmethylsulfonylfluoride [PMSF]). To the homogenate was added 10\% Nonidet P-40 (NP-40) solution, and the mixture was then centrifuged for 2 minutes at 14,000 $\mathrm{rpm}$. The precipitated nuclei were washed twice with buffer A plus $40 \mu \mathrm{L}$ of $10 \% \mathrm{NP}-40$, centrifuged, resuspended in $200 \mu \mathrm{L}$ of buffer C (50 mM HEPES [pH 7.8], $50 \mathrm{mM} \mathrm{KCl,} 300 \mathrm{mM} \mathrm{NaCl}, 0.1$ mM EDTA, $1 \mathrm{mM}$ DTT, $0.1 \mathrm{mM}$ PMSF, 20\% glycerol) and centrifuged for 5 minutes at $14,000 \mathrm{rpm}$. The supernatant containing nuclear proteins was collected and stored at $-70^{\circ} \mathrm{C}$ for further use.

\section{Electrophoretic mobility shift assay}

The electrophoretic mobility shift assay was conducted using a DNA-protein binding assay kit (Gibco BRL, Grand Island, NY, USA). In brief, the NF- $\kappa$ B oligonucleotide probe 5'-GAG GGG ATT CCC TTA- 3 ' and the STAT3 oligonucleotide probe 5 -GAT CCT TCT GGG AAT TCC TAG ATC-3' were labeled with $\left[\gamma^{32} \mathrm{P}\right]$ ATP by T4
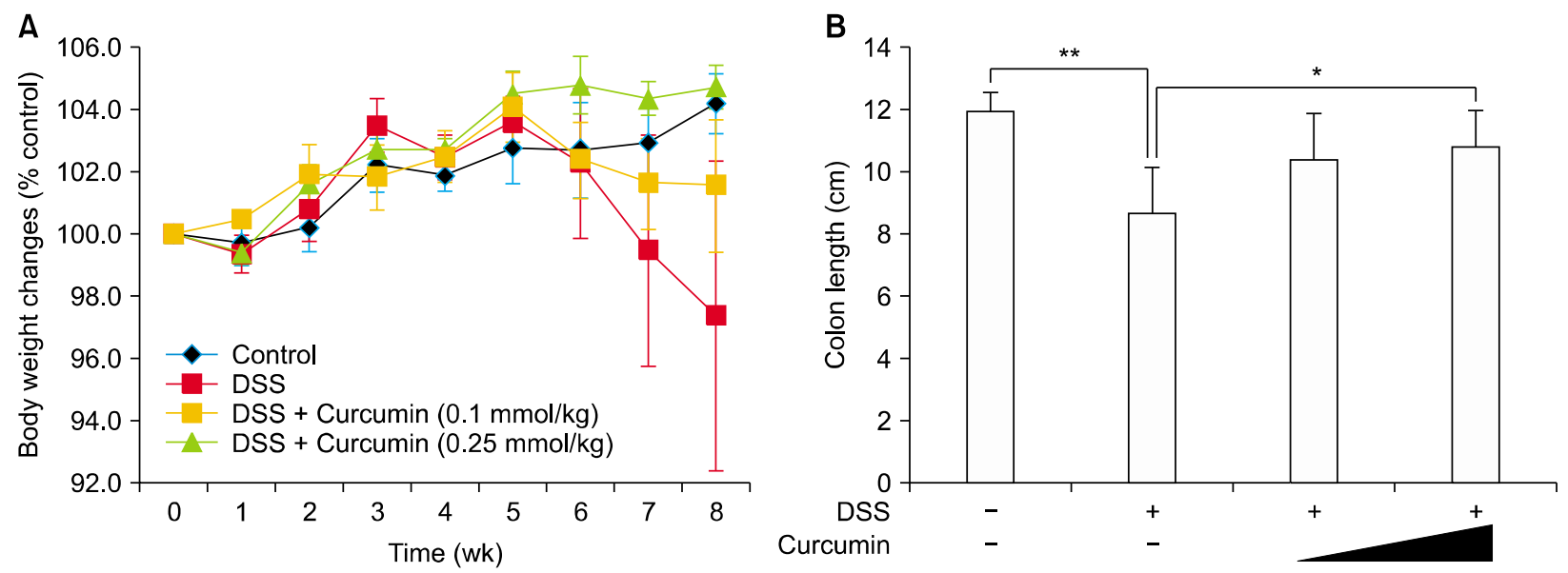

Figure 1. Effect of curcumin on (A) body weight loss and (B) colon length reduction in dextran sulfate sodium (DSS)-treated mice. Animal treatment and other experimental details are described in Materials and Methods section. ${ }^{*} P<0.05$ and $* * P<0.01$.

A

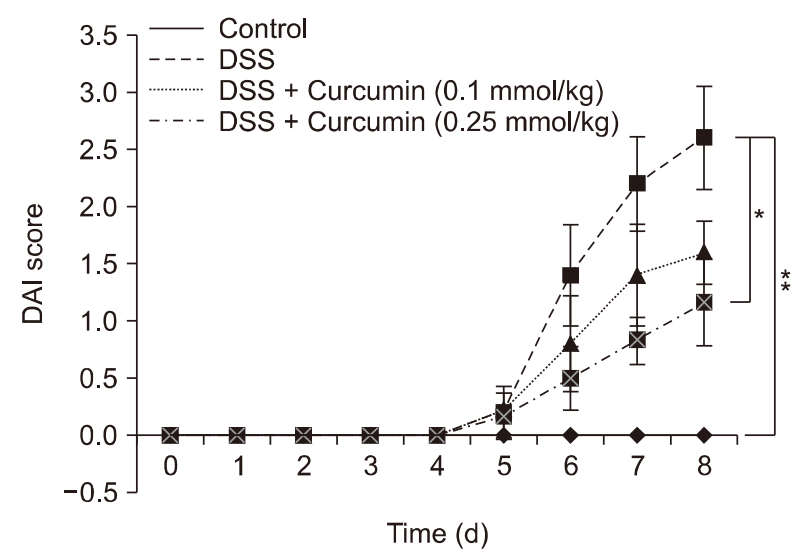

B

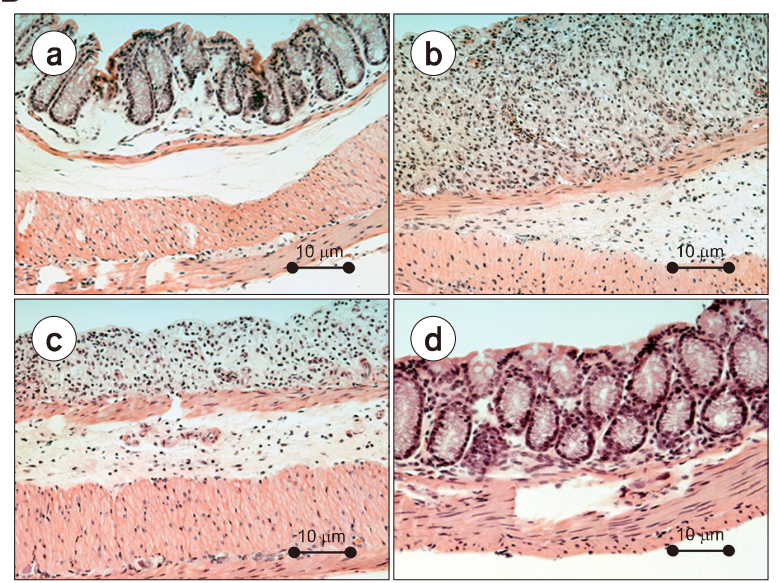

Figure 2. Effect of curcumin on pathophysiologic conditions and histologic changes in dextran sulfate sodium (DSS)-induced murine colitis. (A) Disease activity index (DAI) as the sum of stool consistency and rectal bleeding was scored 0 to 3 . Data are expressed as means \pm SD ( $\mathrm{n}=5$ per group). $* P<0.05$ or $* * P<0.01$ vs. the DSS-treated group. The distal colon was stained by H\&E. (B) Microscopic analysis of $\mathrm{H} \& \mathrm{E}$-stained tissue sections shows that oral administration of curcumin $(0.25 \mathrm{mmol} / \mathrm{kg})$ significantly ameliorated damage of colonic mucosa caused by DSS. (a) Control; (b) DSS alone; (c) DSS + curcumin $(0.1 \mathrm{mmmol} / \mathrm{kg})$; (d) DSS + curcumin $(0.25 \mathrm{mmol} / \mathrm{kg})$. 
polynucleotide kinase and purified on a Nick column (Amersham Pharmacia Biotech, Little Chalfont, UK). The reaction was carried out in $25 \mu \mathrm{L}$ of the mixture containing $10 \mathrm{mM}$ Tris- $\mathrm{HCl}$ ( $\mathrm{pH} 7.5)$, $100 \mathrm{mM} \mathrm{NaCl}, 1 \mathrm{mM}$ DTT, $1 \mathrm{mM}$ EDTA, 4\% glycerol, and 0.1 $\mathrm{mg} / \mathrm{mL}$ sonicated salmon sperm DNA], $10 \mu \mathrm{g}$ of nuclear extracts, and 100,000 cpm. of $\left[\gamma_{-}{ }^{32} \mathrm{P}\right]$ ATP-end labeled oligonucleotide. The reaction mixtures were incubated at room temperature for 50 min. After addition of $2 \mu \mathrm{L}$ of $0.1 \%$ bromophenol blue, the samples were electrophoresised using $6 \%$ non-denaturing polyacrylamide gel at $150 \mathrm{~V}$ in a cold room for 2 hours. Finally, the gel was dried and exposed to X-ray film.

\section{Statistical analysis}

Results are expressed as the means \pm SD. Data were analyzed by one-way ANOVA and Student's $t$-test.

\section{RESULTS}

\section{Curcumin attenuates dextran sulfate sodium- induced mouse colitis}

DSS treatment for one week caused the macroscopic symptoms of colitis, such as a decrease in body weight and colon length, rectal bleeding and diarrhea. Based on the severity of stool consistency and rectal bleeding, DSS-induced pathogenic conditions were scored from 0 to $4 .{ }^{22}$ The sum was given into a form of the disease activity index. Oral administration of curcumin at $0.25 \mathrm{mmol} / \mathrm{kg}$ significantly attenuated the body weight loss (Fig. 1A) and shortening of colon (Fig. 1B), loose stool, diarrhea, and occult rectal blood (Fig. 2A). Exposure to DSS in drinking water for seven days also resulted in marked inflammation of the colon as reflected by thickening of the mucosal wall (Fig. 2B). His-
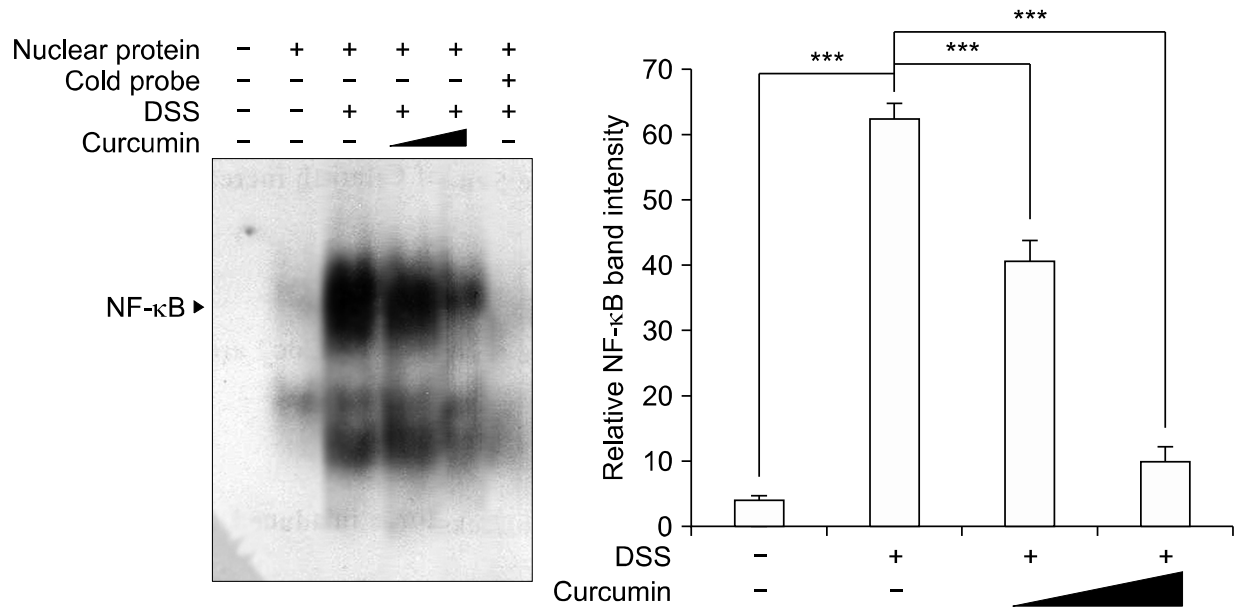

Figure 3. Inhibitory effects of curcumin on dextran sulfate sodium (DSS)induced DNA binding of NF-KB in mouse colon. The nuclear extracts was prepared from colon of each treatment group. Inhibitory effects of curcumin on DSS-induced NF-KB DNA binding were assessed by electrophoretic mobility shift assay as described in Materials and Methods. To ensure the specific NF-KB DNA binding, a competition assay was performed with 100-fold excess unlabeled oligonucleotides. Data are means $\pm \mathrm{SD}$ ( $\mathrm{n}=5$ per group). ${ }^{* * *} P<$ 0.001 vs. the DSS-treated group.

A<smiles>COc1cc(CC(=O)CC(=O)Cc2ccc(C(C)C)cc2)ccc1O</smiles><smiles>COc1cc(CCC(=O)CC(=O)CCc2ccc(O)c(OC)c2)ccc1O</smiles>

B

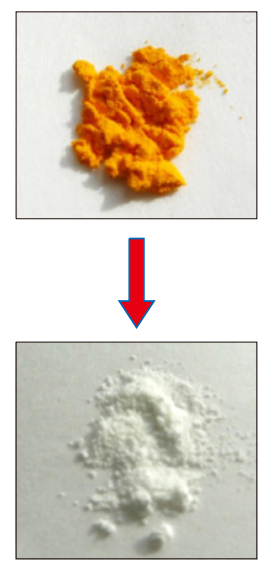

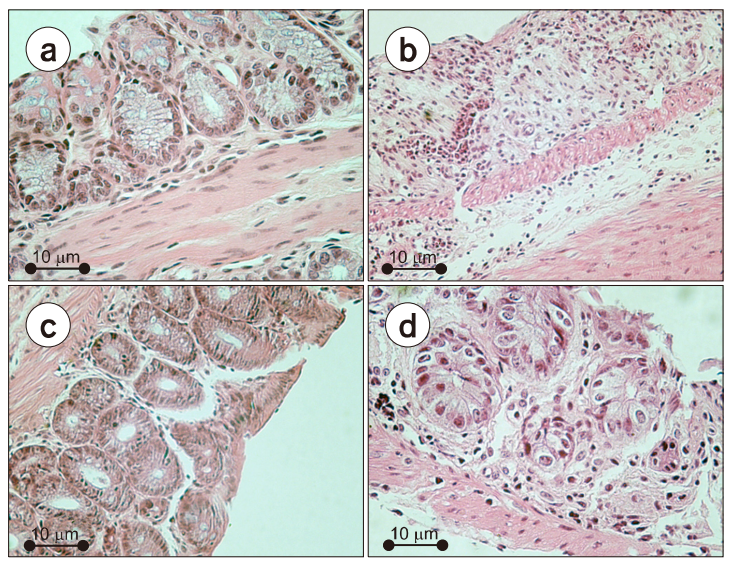

Figure 4. (A) The synthesis of tetrahydrocurcumin by catalytic hydrogenation of curcumin. (B) Effects of curcumin and tetrahydrocurcumin on dextran sulfate sodium (DSS)-induced colitis. Curcumin and tetrahydrocurcumin were treated to mice by gastric intubation at a dose of $0.25 \mathrm{mmol} / \mathrm{kg}$ each. Histology of H\&E-stained mouse colon was visualized under a microscope. (a) Control; (b) DSS alone; (c) DSS + curcumin; (d) DSS + tetrahydrocurcumin. 
topathological examination of formalin-fixed and paraffinembeded colon tissues revealed marked destruction of colonic crypts after DSS treatment, with a progressive demolition of the mucosal barrier. Treatment with curcumin ameliorated DSSinduced inflammatory damage of the colon, and restored the architecture of the mucosal layer (Fig. 2B).

\section{Curcumin inhibits dextran sulfate sodium-induced DNA binding of NF-KB in mouse colon}

NF-kB has been identified as a tumor promoter in inflammation-associated cancer. ${ }^{23}$ The activation of NF- $\mathrm{KB}$ partly contributes to the transactivation of various proinflammatory genes (e.g., COX-2 and iNOS). As shown in Figure 3, DSS administration led to enhancement of NF-KB DNA binding, which was significantly attenuated by curcumin treatment.
3. Tetrahydrocurcumin suppresses colitis and activation of proinflammatory signaling to a lesser extent than curcumin in the colon of dextran sulfate sodium-treated mice

Curcumin possesses a highly electrophilic $\alpha, \beta$-unsaturated carbonyl moiety, which can react with free sulfhydryl groups of many cellular proteins. ${ }^{24}$ To examine whether this electrophilic moiety is important for the anti-inflammatory properties of curcumin, we compared its effects on the DSS-induced colitis, activation of NF- $\kappa \mathrm{B}$ and and expression of proinflammatory enzymes, with those of the non-electrophilic analogue, tetrahydrocurcumin (Fig. 4A). As compared to curcumin, tetrahydrocurcumin exerted much lesser inhibitory effects on colitis (Fig. 4B) and NF-אB DNA binding (Fig. 5A), Another transcription factor involved in inflammation-associated carcinogenesis is STAT3. Curcumin inhibited DSS-induced DNA binding of STAT3 in mouse colon (Fig. 5B). DSS-induced expression of COX-2 and iNOS, two representative pro-inflammatory enzymes known to be regulated by NF- $\mathrm{KB}$ and STAT3 was also attenuated by curcumin
A

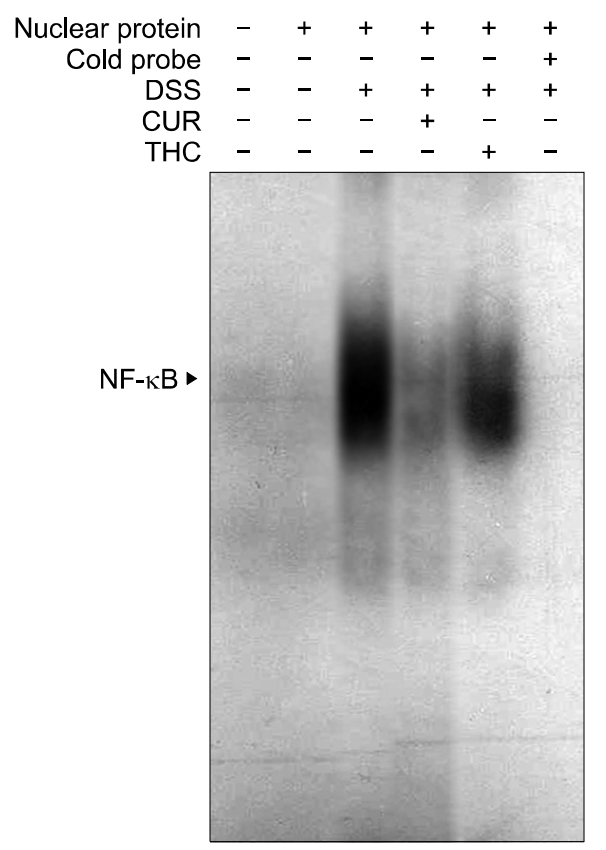

C

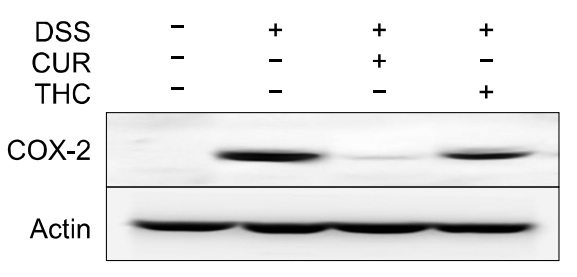

B

$\begin{array}{rllllll}\text { Nuclear protein } & - & + & + & + & + & + \\ \text { Cold probe } & - & - & - & - & - & + \\ \text { DSS } & - & - & + & + & + & + \\ \text { CUR } & - & - & - & + & - & - \\ \text { THC } & - & - & - & - & + & -\end{array}$

STAT3 •
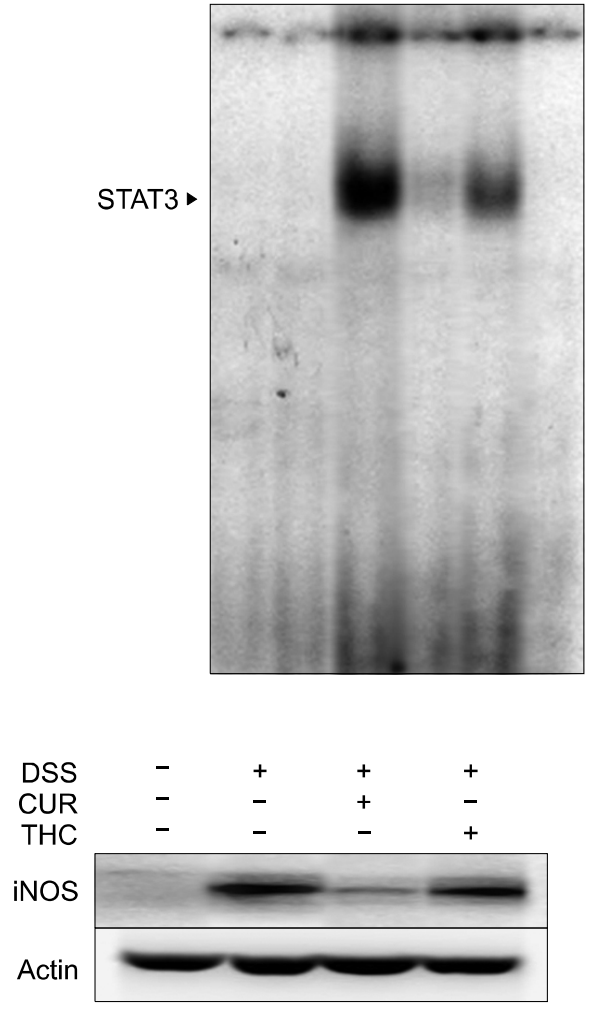

Figure 5. Effects of curcumin (CUR) and tetrahydrocurcumin (THC) on activation of pro-inflammatory transcription factors and expression of their target proteins in the colon of dextran sulfate sodium (DSS)-treated mice. (A, B) The nuclear extracts from the colon of mice were prepared and subjected to electrophoretic mobility shift assay to assess DNA binding of NF- $\mathrm{KB}$ and STAT3 as described in Materials and Methods. (C) Colon tissues from mice treated with either CUR or THC and challenged with DSS were lysed. Lysates were subjected to immunoblot analysis to detect the expression of COX-2 and inducible nitric oxide synthase (iNOS). 
administration (Fig. 5C).

\section{DISCUSSION}

Over the past few decades, there has been a remarkable progress in our understanding the pathogenesis, development and progression of cancer. However, we still do not have effective therapies that can selectively kill cancer cells. Like other human disorders, cancer is basically preventible. Recently, attention has focused on naturally occurring substances, especially derived from plants, capable of intervening in multi-stage carcinogenesis. ${ }^{25} \mathrm{~A}$ wide variety of dietary phytochemicals present in fruits, vegetables, and spices have been known to exert cancer preventive effects through multiple mechanisms. ${ }^{10,25,26}$

Curcumin is an ingredient of the Indian spice turmeric (Curcuma longa L., Zingiberaceae) $^{27}$ responsible for the characteristic yellow color of curry. Curcumin, as a pharmacologically active ingredient of turmeric, has traditionally been used in the management of inflammatory symptoms. ${ }^{28}$ Cancer chemopreventive effects of curcumin in relation to its anti-inflammatory activity have been evaluated in various experimental models. Curcumin when given orally suppressed dimethylhydrazineinitiated and DSS-promoted murine colon carcinogenesis. ${ }^{29}$ $\mathrm{NF}-\kappa \mathrm{B}$ plays crucial roles in the regulation of inflammatory gene transcription, as well as cancer progression. ${ }^{30}$ Suppression of DSS-promoted expression of COX-2 and iNOS by curcumin is attributable to its blockade of the NF- $\kappa B$ overactivation.

Besides NF-кB, STAT3 has been reported to be highly activated in patients with IBDs, such as ulcerative colitis and Crohn's disease, ${ }^{31}$ as well as in DSS-induced colitis in mice. ${ }^{32}$ STAT3 plays a key role in colonic inflammation and colitis-associated cancer. $^{33,34}$ During the colitis-associated tumorigenesis, the activation of STAT3 promotes cell proliferation and survival through upregulation of its target genes, including cyclin D1 and $b c l-x l .{ }^{35}$ In our previous study, curcumin was found to inhibit DNA binding of STAT3 in DSS-stimulated mouse colon. ${ }^{36}$ While our work was in progress, there have been several papers published demonstrating the protective effects of curcumin on DSS-induced murine colitis. Thus, oral administration of curcumin inhibited the DSS-induced colitis, and repressed the signal transduction mediated by JAK-STAT3, ${ }^{19,21}$ as well as IKK $\beta$ activity. ${ }^{37}$

Tetrahydrocurcumin, one of the metabolites of curcumin, is structurally distinct from curcumin, in that it lacks the $\alpha, \beta$ unsaturated carbonyl group. The biological activities of this nonelectrophilic analog of curcumin have been extensively investigated, but the results are discordant. Some studies have demonstrated that tetrahydrocurcumin exerts more potent effects than does curcumin, while others report that both compounds have a similar potency. ${ }^{38}$ In our present study, tetrahydrocurcumin exhibited weaker inhibitory effects compared with curcumin on DSS-induced colitis, DNA binding activity of NF- $\mathrm{KB}$ and STAT3, and expression of COX-2 and iNOS. It appears that the relative potency of curcumin and tetrahydrocurcumin relies on the mode of their interactions with the target molecules. If the interaction is covalent in nature, curcumin is expected to be superior to tetrahydrocurcumin, as the latter compound is unable to act as a Michael reaction acceptor due to the lack of the electrophilic functionality. Otherwise, the response may vary depending on the dose, route of administration, duration of treatment, intracellular environment, especially redox status, etc.

Taken together, the above findings suggest that oral administration of curcumin provokes anti-inflammatory effects by inhibiting the activation of NF- $\mathrm{KB}$ and STAT3 and their target protein expression. Considering a close association between inflammation and cancer and the role of aberrantly overexpressed NF- $\kappa$ B and STAT3 in tumor promotion, the present study provides the molecular basis for the previously reported chemopreventive effects of curcumin on inflammation-associated carcinogenesis.

\section{ACKNOWLEDGMENTS}

This work was supported by the Global Core Research Center (GCRC) grant (No. 2011-003-0001) from the National Research Foundation, Ministry of Education, Science and Technology, Korea.

\section{CONFLICTS OF INTEREST}

No potential conflicts of interest were disclosed.

\section{REFERENCES}

1. Kraus S, Arber N. Inflammation and colorectal cancer. Curr Opin Pharmacol 2009;9:405-10.

2. Tanaka T, Kohno H, Suzuki R, Yamada Y, Sugie S, Mori H. A novel inflammation-related mouse colon carcinogenesis model induced by azoxymethane and dextran sodium sulfate. Cancer Sci 2003;94:965-73.

3. Oshima M, Dinchuk JE, Kargman SL, Oshima H, Hancock B, Kwong E, et al. Suppression of intestinal polyposis in Apc delta716 knockout mice by inhibition of cyclooxygenase 2 (COX-2). Cell 1996;87:803-9.

4. Tive L. Celecoxib clinical profile. Rheumatology (Oxford) 2000;39 Suppl 2:21-8; discussion 57-9.

5. Watanabe K, Kawamori T, Nakatsugi S, Wakabayashi K. COX-2 and iNOS, good targets for chemoprevention of colon cancer. 
Biofactors 2000;12:129-33.

6. Rao CV. Nitric oxide signaling in colon cancer chemoprevention. Mutat Res 2004:555:107-19.

7. Chun KS, Cha HH, Shin JW, Na HK, Park KK, Chung WY, et al. Nitric oxide induces expression of cyclooxygenase-2 in mouse skin through activation of NF-kappaB. Carcinogenesis 2004:25: 445-54.

8. Schreiber S, Nikolaus S, Hampe J. Activation of nuclear factor kappa B inflammatory bowel disease. Gut 1998:42:477-84.

9. Eferl R, Wagner EF. AP-1: a double-edged sword in tumorigenesis. Nat Rev Cancer 2003;3:859-68.

10. Surh YJ. Cancer chemoprevention with dietary phytochemicals. Nat Rev Cancer 2003;3:768-80.

11. Surh Y. Molecular mechanisms of chemopreventive effects of selected dietary and medicinal phenolic substances. Mutat Res 1999:428:305-27.

12. Hanai H, Iida T, Takeuchi K, Watanabe F, Maruyama Y, Andoh A, et al. Curcumin maintenance therapy for ulcerative colitis: randomized, multicenter, double-blind, placebo-controlled trial. Clin Gastroenterol Hepatol 2006;4:1502-6.

13. Sugimoto K, Hanai H, Tozawa K, Aoshi T, Uchijima M, Nagata T, et al. Curcumin prevents and ameliorates trinitrobenzene sulfonic acid-induced colitis in mice. Gastroenterology 2002;123: 1912-22.

14. Deguchi Y, Andoh A, Inatomi O, Yagi Y, Bamba S, Araki Y, et al. Curcumin prevents the development of dextran sulfate Sodium (DSS)-induced experimental colitis. Dig Dis Sci 2007;52:2993-8.

15. Larmonier CB, Midura-Kiela MT, Ramalingam R, Laubitz D, Janikashvili N, Larmonier N, et al. Modulation of neutrophil motility by curcumin: implications for inflammatory bowel disease. Inflamm Bowel Dis 2011;17:503-15.

16. Arafa HM, Hemeida RA, El-Bahrawy AI, Hamada FM. Prophylactic role of curcumin in dextran sulfate sodium (DSS)-induced ulcerative colitis murine model. Food Chem Toxicol 2009;47:1311-7.

17. Villegas I, Sánchez-Fidalgo S, de la Lastra CA. Chemopreventive effect of dietary curcumin on inflammation-induced colorectal carcinogenesis in mice. Mol Nutr Food Res 2011;55:259-67.

18. McFadden RM, Larmonier CB, Shehab KW, Midura-Kiela M, Ramalingam R, Harrison CA, et al. The role of curcumin in modulating colonic microbiota during colitis and colon cancer prevention. Inflamm Bowel Dis 2015:21:2483-94.

19. Liu L, Liu YL, Liu GX, Chen X, Yang K, Yang YX, et al. Curcumin ameliorates dextran sulfate sodium-induced experimental colitis by blocking STAT3 signaling pathway. Int Immunopharmacol 2013;17:314-20.

20. Ukil A, Maity S, Karmakar S, Datta N, Vedasiromoni JR, Das PK. Curcumin, the major component of food flavour turmeric, reduces mucosal injury in trinitrobenzene sulphonic acid-induced colitis. Br J Pharmacol 2003;139:209-18

21. Zhao HM, Xu R, Huang XY, Cheng SM, Huang MF, Yue HY, et al. Curcumin suppressed activation of dendritic cells via JAK/STAT/ SOCS signal in mice with experimental colitis. Front Pharmacol 2016;7:455
22. Lavi I, Levinson D, Peri I, Nimri L, Hadar Y, Schwartz B. Orally administered glucans from the edible mushroom Pleurotus pulmonarius reduce acute inflammation in dextran sulfate sodium-induced experimental colitis. Br J Nutr 2010;103:393-402.

23. Pikarsky E, Porat RM, Stein I, Abramovitch R, Amit S, Kasem S, et al. NF-kappaB functions as a tumour promoter in inflammationassociated cancer. Nature 2004:431:461-6.

24. Shibata T, Yamada T, Ishii T, Kumazawa S, Nakamura H, Masutani $\mathrm{H}$, et al. Thioredoxin as a molecular target of cyclopentenone prostaglandins. J Biol Chem 2003:278:26046-54.

25. Chen C, Kong AN. Dietary cancer-chemopreventive compounds: from signaling and gene expression to pharmacological effects. Trends Pharmacol Sci 2005:26:318-26.

26. Aggarwal BB, Takada Y, Oommen OV. From chemoprevention to chemotherapy: common targets and common goals. Expert Opin Investig Drugs 2004:13:1327-38.

27. Govindarajan VS. Turmeric: chemistry, technology, and quality. Crit Rev Food Sci Nutr 1980;12:199-301

28. Aggarwal BB, Kumar A, Bharti AC. Anticancer potential of curcumin: preclinical and clinical studies. Anticancer Res 2003;23: 363-98.

29. Murakami A, Furukawa I, Miyamoto S, Tanaka T, Ohigashi H. Curcumin combined with turmerones, essential oil components of turmeric, abolishes inflammation-associated mouse colon carcinogenesis. Biofactors 2013;39:221-32.

30. Karin M, Greten FR. NF-kappaB: linking inflammation and immunity to cancer development and progression. Nat Rev Immunol 2005:5:749-59.

31. Mudter J, Weigmann B, Bartsch B, Kiesslich R, Strand D, Galle PR, et al. Activation pattern of signal transducers and activators of transcription (STAT) factors in inflammatory bowel diseases. Am J Gastroenterol 2005;100:64-72.

32. Takaki K, Mitsuyama K, Tsuruta O, Toyonaga A, Sata M. Attenuation of experimental colonic injury by thiazolidinedione agents. Inflamm Res 2006;55:10-5.

33. Bromberg J, Wang TC. Inflammation and cancer: IL-6 and STAT3 complete the link. Cancer Cell 2009;15:79-80.

34. Pickert G, Neufert C, Leppkes M, Zheng Y, Wittkopf N, Warntjen $\mathrm{M}$, et al. STAT3 links IL-22 signaling in intestinal epithelial cells to mucosal wound healing. J Exp Med 2009:206:1465-72.

35. Xiao H, Gulen MF, Qin J, Yao J, Bulek K, Kish D, et al. The Toll-interleukin-1 receptor member SIGIRR regulates colonic epithelial homeostasis, inflammation, and tumorigenesis. Immunity 2007; 26:461-75.

36. Yang JY, Zhong X, Yum HW, Lee HJ, Kundu JK, Na HK, et al. Curcumin inhibits STAT3 signaling in the colon of dextran sulfate sodium-treated mice. J Cancer Prev 2013;18:186-91.

37. Kao NJ, Hu JY, Wu CS, Kong ZL. Curcumin represses the activity of inhibitor- $\mathrm{KB}$ kinase in dextran sulfate sodium-induced colitis by S-nitrosylation. Int Immunopharmacol 2016;38:1-7.

38. Cooper HS, Murthy SN, Shah RS, Sedergran DJ. Clinicopathologic study of dextran sulfate sodium experimental murine colitis. Lab Invest 1993;69:238-49. 